$1-27-2020$

\title{
Anxiety-Related Issues in Cancer Survivorship
}

Maresi A. Berry-Stoelzle

Anna C. Mark

Peter Kim

Jeanette M. Daly

Follow this and additional works at: https://aah.org/jpcrr

Part of the Neoplasms Commons, Oncology Commons, Other Psychiatry and Psychology Commons, Primary Care Commons, and the Psychiatric and Mental Health Commons

\section{Recommended Citation}

Berry-Stoelzle MA, Mark AC, Kim P, Daly JM. Anxiety-related issues in cancer survivorship. J Patient Cent Res Rev. 2020;7:31-8. doi: 10.17294/2330-0698.1711

Published quarterly by Midwest-based health system Advocate Aurora Health and indexed in PubMed Central, the Journal of Patient-Centered Research and Reviews (JPCRR) is an open access, peer-reviewed medical journal focused on disseminating scholarly works devoted to improving patient-centered care practices, health outcomes, and the patient experience. 


\title{
Anxiety-Related Issues in Cancer Survivorship
}

\author{
Maresi A. Berry-Stoelzle, MD, PhD, Anna C. Mark, MD, Peter Kim, MD, MPH, Jeanette M. Daly, PhD, RN \\ Department of Family Medicine, University of lowa Carver College of Medicine, lowa City, IA
}

\begin{abstract}
Purpose The purpose of this qualitative study was to examine patient opinions about anxiety in cancer survivorship, particularly the role of the primary care provider in management of anxiety related to the trajectory of long-term cancer survivorship.
\end{abstract}

Methods Respondents to a mass email $(\mathrm{N}=22,000)$ were invited to participate in 1 of 3 institutional review board-approved focus group meetings. Inclusion criteria were being an adult patient older than 25 years of age, having any type of cancer diagnosis, and being at least 18 months from treatment. The following specific issues were discussed: role of the primary care provider during and after therapy; the transition to primary care after therapy was finished; and advice the survivors would give to providers and cancer survivors. Focus group meetings were audio-recorded and later transcribed and reviewed by members of the research team using constant comparison methods.

Results Three 2-hour focus groups were conducted to interview 22 cancer survivors. We found 5 main themes related to anxiety in cancer survivorship: memory of anxiety; anxiety related to possible cancer recurrence; role of close relationship with the health care provider in anxiety management; frequency of communication in reduction of anxiety symptoms; and effect of anxiety on future health decisions posttreatment.

Conclusions Survivors described anxiety persisting throughout cancer diagnosis and treatment and well into survivorship. They reported receiving care from primary care providers as well as oncologists. Anxiety was discussed by most participants as a significant part of their experience with cancer. (J Patient Cent Res Rev. 2020;7:31-38.)

Keywords cancer survivorship; anxiety; qualitative study; patient perspectives; primary care; oncology

$\mathrm{T}$ The projected number of patients with a history of cancer in the United States is expected to increase from 13.7 million in 2012 to 18 million by 2022 , with a $37 \%$ increase for those who will live 5 or more years after diagnosis. ${ }^{1}$ The fragmentation of posttherapy care often leads to uncertainty on who is responsible for managing anxiety as well as other psychosocial needs. Anxiety disorders, as defined by the Diagnostic and Statistical Manual of Mental Disorders, Fifth

Correspondence: Maresi A. Berry-Stoelzle, MD, PhD, University of lowa Carver College of Medicine, 01291-C Pomerantz Family Pavilion, 200 Hawkins Drive, lowa City, IA 52242 (maresi-berry@uiowa.edu)
Edition, share features of excessive fear and anxiety. While fear is the response to an imminent threat, anxiety is anticipation of future threat manifesting as excessive and persistent fear or worry. ${ }^{2}$ Attention to anxiety is an important psychosocial aspect of cancer survivorship care. ${ }^{3,4}$

The prevalence of anxiety is higher in survivors of cancer compared to healthy controls, and this difference persists in patients whose cancer was diagnosed 10 or more years previously. ${ }^{5}$ Anxiety can negatively impact quality of life in cancer survivors, ${ }^{6}$ impacting mental health and functioning and increasing the severity of somatic symptoms. ${ }^{7}$ In 2008, the Institute of Medicine reported that addressing psychosocial needs of patients is part of quality cancer care. ${ }^{8}$ Current American Society of Clinical 
Oncology (ASCO) guidelines state that all health providers should routinely screen patients with cancer and survivors for anxiety. ${ }^{9}$ Less than half of survivors report having a discussion about psychosocial needs with a health care provider. ${ }^{10}$ Discussing psychosocial needs helps identify otherwise undetected needs and provides an opportunity for treatment or referral for those needs. ${ }^{10}$

Previous work has found that more than half of survivors report fear of recurrence even years after cancer diagnosis. ${ }^{11}$ Increased anxiety in these participants influenced their decisions, which may affect their quality of life. ${ }^{12}$ Survivors' reported quality of life at 1, 3, and 5 years after diagnosis showed a perceived decrease in all domains, particularly with regard to anxiety and depression. ${ }^{6,13,14}$ Arrieta et al reported an association between depression and poor treatment adherence in patients with lung cancer. ${ }^{15}$ Literature from other life-altering diseases noted a deleterious effect of anxiety on quality of life in patients on dialysis and those who received kidney transplants. ${ }^{15-17}$ In patients with cancer, Mutsaers et al differentiated when fear of cancer recurrence becomes clinical. ${ }^{18}$ It is here where cancer survivors benefit from therapy. ${ }^{19}$

As the number of survivors increases and past patients become more removed in time and geography from their initial cancer treatment, primary care providers (PCP) are well placed to address and manage anxiety within this patient population. ${ }^{20}$ Studies of cancer survivorship trajectories identify different pathways for cancer-related worry and posttraumatic growth. ${ }^{19}$ This includes adapting care, including the diagnosis and management of anxiety that often occurs. ${ }^{21}$ PCPs are experienced in adapting therapy to patient needs.

The purpose of this study was to examine patient opinions about where and which health care provider group should diagnose and address anxiety-related issues in cancer survivorship. Our theoretical framework leans on the work of Martin et al and Ratcliff et al, in which cancer survivorship is described as a trajectory. ${ }^{12,19}$ Of importance, the provider must not only assess whether anxiety or depression is present but determine whether it is clinically significant and warrants intervention. ${ }^{18} \mathrm{We}$ are particularly interested in the current and potential roles of PCPs in survivorship care along this patientcentered trajectory.

\section{METHODS}

After institutional review board approval was obtained in April 2017, a mass email message $(\mathrm{N}=22,000)$ was distributed to the University of Iowa campus community once. Convenience sampling was used for the focus groups. ${ }^{22}$ Participants were then selected on a first-come first-served basis. Participants included patients who met the following eligibility criteria: 1) adult patient greater than 25 years old; 2) history of cancer diagnosis; and 3) at least 18 months from completion of definitive cancer therapy, including radiation, surgery, or chemotherapy. After participation in the focus group, a $\$ 20$ gift card was provided to participants to partially compensate them for their time.

Two-hour focus groups of posttreatment cancer survivors were conducted in a conference room at the University of Iowa Health Care's Department of Family Medicine (Iowa City, IA). This provided a neutral space for the focus groups. ${ }^{23}$ At each focus group, participants were initially asked to briefly introduce themselves and describe their unique experience with cancer. The moderator (M.B-S., female) then used targeted questions and prompts to ensure specific issues guided the focus group interviews. ${ }^{23}$ These issues included the role of the PCP during and after cancer therapy, the transition to primary care after therapy was finished, and advice the study participants would give to PCPs and survivors of cancer. With the consent of the participants, focus groups were audio-recorded and 2 designated notetakers were present at each meeting. ${ }^{23}$ The recordings were later transcribed and reviewed by members of the research team ( 1 family physician, 2 medical students, and 1 research scientist).

Transcripts were read and coded separately by 4 different members of the research team. The raw coding techniques used by the researchers varied from line-by-line gerund coding to thematic coding. ${ }^{24}$ Table 1 shows the code book used and applied to the transcripts. After the initial coding was completed, discussions about emerging themes took place. All 
Table 1. Code Book Used to Identify Themes Related to Anxiety in Cancer Survivorship

\begin{tabular}{|c|c|c|c|c|c|}
\hline $\bar{A}$ & Unmet needs & $\begin{array}{l}\text { A1 } \\
\text { A2 } \\
\text { A3 } \\
\text { A4 }\end{array}$ & $\begin{array}{l}\text { Social } \\
\text { Physical } \\
\text { Mental } \\
\text { Other }\end{array}$ & & \\
\hline $\mathrm{B}$ & Everyday routines & $\begin{array}{l}\text { B1 } \\
\text { B2 } \\
\text { B3 }\end{array}$ & $\begin{array}{l}\text { Interaction with family } \\
\text { Interaction with work } \\
\text { Other interactions }\end{array}$ & & \\
\hline $\mathrm{C}$ & Treatment end & $\begin{array}{l}\text { C1 } \\
\text { C2 } \\
\text { C3 } \\
\text { C4 }\end{array}$ & $\begin{array}{l}\text { What comes after } \\
\text { Who drives the transition } \\
\text { Integrating follow-up care into end of treatment } \\
\text { Formal structured clinic - survivorship }\end{array}$ & & \\
\hline $\mathrm{D}$ & Emotional needs & $\begin{array}{l}\text { D1 } \\
\text { D2 } \\
\text { D3 }\end{array}$ & $\begin{array}{l}\text { Self } \\
\text { Others } \\
\text { Stigma about }\end{array}$ & $\begin{array}{l}\text { D1.1 } \\
\text { D1.2 } \\
\text { D1.3 }\end{array}$ & $\begin{array}{l}\text { Oncologist } \\
\text { PCP } \\
\text { Other provider }\end{array}$ \\
\hline$E$ & Physical needs & $\begin{array}{l}\mathrm{E} 1 \\
\mathrm{E} 2\end{array}$ & $\begin{array}{l}\text { Managing long-term side effects } \\
\text { Other complications }\end{array}$ & & \\
\hline $\bar{F}$ & Self-identity & $\begin{array}{l}\text { F1 } \\
\text { F2 }\end{array}$ & $\begin{array}{l}\text { Change due to cancer } d x / \text { thx } \\
\text { Same - what has not changed since the } d x / \text { thx }\end{array}$ & & \\
\hline $\mathrm{G}$ & Developing a new community & G1 & & & \\
\hline $\mathrm{H}$ & Emotional ties to treating team & $\mathrm{H} 1$ & & & \\
\hline I & Social support & $\begin{array}{l}11 \\
12 \\
13 \\
14\end{array}$ & $\begin{array}{l}\text { Family } \\
\text { Other nonmedical } \\
\text { Cancer center } \\
\text { Other medical }\end{array}$ & & \\
\hline $\mathrm{J}$ & Communication & $\begin{array}{l}\mathrm{J} 1 \\
\mathrm{~J} 2 \\
\mathrm{~J} 3 \\
\mathrm{~J} 4 \\
\mathrm{~J} 5\end{array}$ & $\begin{array}{l}\text { Patient feelings about } \\
\text { Importance of } \\
\text { Different connections } \\
\text { Patient with physicians } \\
\text { Among physicians/providers }\end{array}$ & & \\
\hline $\mathrm{K}$ & Emotional care & $\begin{array}{l}\mathrm{K} 1 \\
\mathrm{~K} 2 \\
\mathrm{~K} 3\end{array}$ & $\begin{array}{l}\text { Before } \\
\text { During } \\
\text { After }\end{array}$ & & \\
\hline $\mathrm{L}$ & Primary care & $\begin{array}{l}\text { L1 } \\
\text { L2 }\end{array}$ & $\begin{array}{l}\text { What to PCP } \\
\text { When to PCP }\end{array}$ & & \\
\hline $\bar{M}$ & $\begin{array}{l}\text { Sources of information (who or } \\
\text { where patients turn for info about } \\
\text { how to manage their cancer) }\end{array}$ & M1 & $\begin{array}{l}\text { Medical therapy } \\
\text { Nonmedical therapy }\end{array}$ & & \\
\hline $\mathrm{N}$ & Physician's role & $\begin{array}{l}\text { N1 } \\
\text { N2 } \\
\text { N3 } \\
\text { N4 }\end{array}$ & $\begin{array}{l}\text { Oncologist } \\
\text { PCP (any primary care specialty acting as PCP } \\
\text { - may include OB/GYN, etc) } \\
\text { Other specialist } \\
\text { Unclear }\end{array}$ & & \\
\hline $\mathrm{O}$ & Emotion to cancer survivorship & $\begin{array}{l}\mathrm{O} 1 \\
\mathrm{O} 2 \\
\mathrm{O} 3 \\
\mathrm{O} 4\end{array}$ & $\begin{array}{l}\text { Matter of fact } \\
\text { Positive } \\
\text { Negative } \\
\text { Mixed }\end{array}$ & & \\
\hline $\mathrm{P}$ & $\begin{array}{l}\text { Awareness of timeline (how and } \\
\text { when patients become aware of } \\
\text { timelines, either by dx, work-up, } \\
\text { thx, or time since certain events) }\end{array}$ & P1 & & & \\
\hline$Q$ & Medical condition & $\begin{array}{l}\text { Q1 } \\
\text { Q2 } \\
\text { Q3 }\end{array}$ & $\begin{array}{l}\text { Cancer } \\
\text { Other diseases } \\
\text { Holistic care }\end{array}$ & & \\
\hline
\end{tabular}

$d x$, diagnosis; OB/GYN, obstetrics and gynecology; PCP, primary care provider; thx, therapy. 
data relevant to anxiety were then extracted. The constant comparison method was used, for a total of 2 cycles, with each coder to make comparisons within and between transcripts in order to identify common themes with respect to anxiety. ${ }^{24}$

\section{RESULTS}

We conducted 3 focus groups totaling 20 women and 2 men, with ages ranging from the 30 s to the 70 s. Time since treatment ranged from 18 months to many years. Cancer types among the participants included breast, prostate, testicular, non-Hodgkin's lymphoma, osteosarcoma, ovarian, thyroid, uterine, fallopian tube, melanoma, and vaginal. Of the 22 participants, 7 had either the same type of recurring cancer or were survivors of multiple cancer types.

The survivors in our focus groups described anxiety persisting through cancer diagnosis, treatment, and well into survivorship. Participants discussed anxiety surrounding many facets of their lives. We found 5 main themes related to anxiety: the memory of anxiety, anxiety related to possible cancer recurrence, the role of the provider in management of anxiety, the importance of communication, and the influence of anxiety on future health decisions.

\section{Memory of Anxiety}

Participants discussed experiencing anxiety during the survivorship phase as a result of the anxiety experienced during cancer diagnosis and treatment. Participants even compared the anxiety felt during the survivorship phase as similar to posttraumatic stress disorder (PTSD), a condition that causes patients to be distressed by the mental recollection of past traumatic events. While the participants did not specifically disclose whether they had a medical diagnosis of anxiety disorder or PTSD, the term PTSD was mentioned by more than one participant. They described the memory of anxiety associated with the cancer diagnosis and treatment as strong enough to evoke intense anxiety years after cancer treatment was completed.

“... My experience of going to oncology versus going to my internal med [physician] is it's almost like I had a little bit of a PTSD response to go back into the oncology clinic."
Participants defined anxiety as one of the long-term mental health effects of cancer and cancer treatment. They discussed how the anxiety they felt during cancer diagnosis and treatment was oftentimes overlooked and not addressed. This anxiety then stayed with participants and continued into the survivorship phase. The memory of the anxiety they experienced drove many of these participants to request a greater emphasis be placed on the mental health aspect of care for cancer patients and survivors.

“... My recommendation to somebody who is just coming out of the treatment would be, really sort of keep an eye on your own mental health. I think that's really important, because those around don't always perceive what's going on or don't understand why you're going through this, because I don't think a lot of people understand, just like you were saying. They don't have any understanding of the depth of what cancer is exactly."

\section{Anxiety Related to Possible Cancer Recurrence}

One of the most common causes of anxiety discussed by participants was anxiety related to possible cancer recurrence. Anxiety associated with possible recurrence was present in survivors regardless of recency of treatment.

"It's [Cancer's] something, you know, you're always worried about something coming back."

The possibility of a cancer recurrence was described as a constant source of anxiety lasting years after cancer treatment was completed. Anxiety associated with cancer recurrence caused distress in the daily lives of survivors and changed the way survivors view their health and body.

“... You do not trust your body after you've had cancer. And it takes a long time to, I mean, I'm not sure I ever [got] trust back - after 20 years, I did start trusting and then I got the ovarian [cancer]."

\section{Role of Health Care Provider (Primary Care or Oncologist) in Anxiety Management}

Participants had differing opinions as to which provider was best equipped to manage anxiety. Some participants expressed having a close relationship with their oncologists. There was more trust in the oncologist compared to other providers due to knowledge of the cancer and treatment course. These participants felt 
more comfortable going directly to their oncologists with health concerns, including anxiety, and had difficulty trusting other providers

"Anytime there was kind of, if I had a worrisome symptom, I would have gone back to see my oncologist."

Other participants described a close relationship with their PCP. These participants felt their PCP had deeper insight into aspects of care, such as mental health and anxiety, when compared to the oncologist. Participants described struggling with anxiety and other mental health issues that went unnoticed by oncology providers. In these situations, the PCP was able to assess and treat the concerns. Participants expressed feeling more comfortable in talking about mental health with the PCP.

"I was on antidepressants and anti-anxiety meds, so my primary care doctor was really helpful with this. It was pretty stressful and depressing, and anxiety-producing. So he kept, um, he kept me going and adjusted the medications for me."

\section{Communication Reduced Anxiety Symptoms}

Anxiety was often coupled with communication during the focus group discussions. Participants described increased communication helped to decrease anxiety. They shared having access to a provider helped to relieve anxiety, while no access became a source of anxiety. The main forms of access discussed were phone calls and emails. Lack of access left participants feeling isolated and alone, which led to increased anxiety.

"I just want somebody that will return my calls, cause I get concerned about my health, I get really anxious."

Participants also discussed anxiety related to communication between patient and provider. Participants who had close relationships with their PCP outlined close communication throughout cancer treatment. They expressed that this helped relieve anxiety.

"She [PCP] called me regularly and would - when I had to have tests, before my surgery, and treatment, and tests all along the way - she was the one who always called me first with the results. When I was panicking, she would call me and say, 'Come see me right now; we are gonna talk.' I don't know what I would have done without her."

Participants explained that knowing communication existed between oncology and primary care helped to relieve anxiety. They described feeling more comfortable in returning to the PCP and having increased trust in the care provided because they were aware communication took place between oncology and primary care. Without clear evidence of communications between oncologists and other providers, participants felt increased anxiety when transitioning out of oncology care.

“... Because I know all of my records are in one place, everything is in there, and I know for a fact that she [PCP] talks to my medical oncologist, who is still following me, and my surgical oncologist, and my radiation oncologist. ... I feel very comfortable [with the PCP] because I know the communication is, is so good."

Transitioning out of oncology care can be very stressful. Participants were often not clear on who to contact during the first months after the end of oncology care, or even when that end should be. Most participants denied having a survivorship care plan or having a discussion about survivorship care with a provider. Some participants described the positive experience of having a PCP who helped to facilitate that transition and who became the person for the survivor to contact with concerns. Participants emphasized the importance of communication and how knowing who to contact could help relieve anxiety.

"I think, you know, everybody is so overwhelmed. When they [the oncologists] release a patient, ideally this person [from the cancer center] should talk to this person [PCP]. [Oncologists should communicate with the PCP,] 'Here, I'm sending them back. These are the things [that are important regarding this patient's cancer management]. Let's talk. ,"

"When they [oncology] turned me loose, I was glad that I had a primary care [sic], because I felt like I was jumping off a cliff. ... And I had that primary care doctor, which was helpful. It made me feel like I had a soft landing under me." 
Influence of Anxiety on Future Health Decisions Participants described the influence anxiety had on decisions they made regarding their health. This included deciding whether to have procedures or further testing, whether to try new medications or supplements, and which location to have tests performed and/or receive care. These participants described how the influence lasted years after treatment completion.

"I didn't have reconstruction until 10 years out, because I was concerned about recurrence, and how would I know? Would I miss it if I had reconstruction? And I, so I went through this whole, am I still female? You know, I don't have breasts, but can I stand up and, you know, be proud of my scars, and I'm a warrior, and I survived, or do I hunch? And it was, it was a battle for 10 years."

\section{DISCUSSION}

For the survivors of cancer in our focus groups, anxiety was a common condition through all the phases of their cancer care - diagnosis, treatment, and survivorship. The memory of the anxiety felt while going through the process of cancer diagnosis and treatment was still felt years after treatment completion. Some participants described PTSD-like feelings in looking back on their experience. Intrusive symptoms associated with the traumatic event start long after the event occurs. These include distressing memories, recurrent dreams, flashbacks, or other similar symptoms. Firmin et al addressed triggering events as generating events. ${ }^{2,14}$ A positive correlation has been reported between survivors of cancer and PTSD. ${ }^{25}$ Our research demonstrates the memory of anxiety in survivors of cancer continues to have an impact after treatment is completed. This is in line with previous research showing the prevalence of anxiety is greater in survivors of cancer versus healthy controls. ${ }^{5}$

Some participants preferred oncologists to provide anxiety-related care, whereas others preferred the PCP. Often, oncologists and PCPs also will have differing opinions on who should be providing what type of care for survivors of cancer. ${ }^{26}$ Ongoing care includes general health maintenance, which would cover mental health and anxiety. ${ }^{27}$ However, a 2004 survey of ASCO members showed that only $61.2 \%$ of its members reported feeling comfortable providing general medical care to survivors. ${ }^{28}$ On the other hand, both patients and general practitioners support a greater role for the general practitioner in followup cancer care. ${ }^{21}$ Regardless of which provider addressed anxiety, participants found relief if anxiety was addressed. Current ASCO guidelines state that all providers should screen for anxiety from the time of cancer diagnosis and onward. ${ }^{9}$ Our research showed this is not always the case for cancer survivors; however, addressing anxiety is exceedingly important as the relative risk of anxiety is statistically significant 10 or more years after the cancer diagnosis. ${ }^{5}$ A study into long-term follow-up duration with oncology in pediatric cancer patients showed less than 50\% of pediatric patients received follow-up care from oncology 10 years after treatment. ${ }^{29}$ Family physicians are an important component of follow-up care, particularly for cancers with extended posttherapy survival, such as breast, prostate, and those with a history of childhood cancer. ${ }^{30-34}$

Consistent with previous research, our study showed that anxiety is an ongoing challenge for survivors of cancer along the survivorship timeline. ${ }^{19,35}$ Our findings also identified where patients successfully find care for their anxiety and explored how patients want their anxiety addressed. The subthemes identified under anxiety included the memory of anxiety, possible cancer recurrence, the role of the provider in anxiety management, extent of communication, and the influence of anxiety on future health decisions. Anxiety was discussed by most participants, particularly the need to address and manage this concern. The focus group data support a role for primary care in assessing and managing anxiety for survivors of cancer. The data also underscore the need for improved communication between all stakeholders, including oncologists, PCPs, and patients, to enhance the quality of care received by survivors of cancer.

Focus groups showed participants felt increased anxiety when communication was decreased. One way to combat this anxiety is discussing survivorship care. According to Blanch-Hartigan et al, $64 \%$ of oncologists reported discussing survivorship care recommendations with survivors while only $32 \%$ of oncologists reported discussing who the survivor should see for cancer-related or other follow-up care. ${ }^{36}$ 
These low percentages are reflected in the anxiety expressed by participants in the focus groups. Anxiety has been described as an unmet need, since less than half of the survivors report a discussion with a provider about psychosocial needs. ${ }^{10}$ This underscores the importance of addressing anxiety in survivors of cancer, ${ }^{13,19}$ as some participants described intense anxiety, and further emphasizes the need for anxiety screening and treatment in this growing patient population. ${ }^{1}$

\section{Limitations}

While symptoms and issues related to anxiety were reported by focus group participants, we do not know how many patients were diagnosed with anxiety disorder. Anxiety related to specific types of cancer diagnosis and stage were not explored. Our results do not provide information on which of the 5 main themes should be prioritized in the clinical setting.

Future areas of study for this topic include a more in-depth investigation into anxiety screening and treatment modalities available to cancer survivors in the primary care setting. Additional work might entail the development of evidence-based interventions for different survivorship trajectories based on expression of the anxiety/depression themes and the clinical severity. This would most likely involve a multimodal approach consisting of traditional pharmacologic, behavioral, and cognitive therapies as well as new methods such as the internet-based cognitive behavioral therapy studied by Karageorge and colleagues. ${ }^{37}$

\section{CONCLUSIONS}

The survivors of cancer who participated in our focus group described anxiety as a significant condition and part of their cancer experience that persisted throughout diagnosis, treatment, and well into survivorship. Cancer survivorship trajectories are not one-size-fits-all, and the associated "best therapy" will be multifactorial. Primary care providers should be well trained to manage anxiety in cancer survivorship. Patients continue to go to their PCP for medical care after cancer diagnosis and therapy, thus PCPs may be best poised to improve the quality of cancer survivorship care as it pertains to alleviating anxiety.

\section{Patient-Friendly Recap}

- Millions of cancer survivors live longer than 5 years after their cancer treatment ends, yet how anxiety is best managed during extended survivorship is unknown.

- Through focus group interviews, the authors identified 5 main issues related to anxiety: 1) memory of anxiety lingers for years; 2) possibility of cancer recurrence induces anxiety; 3) relationship with health care provider impacts anxiety management; 4) frequency of communication can reduce anxiety symptoms; and 5) anxiety affects future health decisions.

- The authors suggest that, while different patient survivorship trajectories require different approaches to care, primary care providers should be well positioned to manage appropriate anxiety therapy for cancer survivors.

\section{Acknowledgments}

John Ely, MD, MPH, and Barcey Levy, MD, PhD, of University of Iowa Carver College of Medicine.

\section{Author Contributions}

Study design: Berry-Stoelzle, Mark, Daly. Data acquisition or analysis: all authors. Manuscript drafting: all authors. Critical revision: all authors.

\section{Conflicts of Interest}

None.

\section{Funding Sources}

Funding for this project was provided by the University of Iowa's Holden Comprehensive Cancer Center's Diana Benz Memorial Fund seed grant program.

\section{References}

1. de Moor JS, Mariotto AB, Parry C, et al. Cancer survivors in the United States: prevalence across the survivorship trajectory and implications for care. Cancer Epidemiol Biomarkers Prev. 2013;22:561-70. CrossRef

2. American Psychiatric Association. Diagnostic and Statistical Manual of Mental Disorders, Fifth Edition (DSM-5). Arlington, VA: American Psychiatric Publishing, 2013. CrossRef

3. Koch L, Bertram H, Eberle A, et al. Fear of recurrence in longterm breast cancer survivors - still an issue. Results on prevalence, determinants, and the association with quality of life and depression from the cancer survivorship - a multi-regional population-based study. Psychooncology. 2014;23:547-54. CrossRef 
4. Mehnert A, Berg P, Henrich G, Herschbach P. Fear of cancer progression and cancer-related intrusive cognitions in breast cancer survivors. Psychooncology. 2009;18:1273-80. CrossRef

5. Mitchell AJ, Ferguson DW, Gill J, Paul J, Symonds P. Depression and anxiety in long-term cancer survivors compared with spouses and healthy controls: a systematic review and meta-analysis. Lancet Oncol. 2013;14:721-32. CrossRef

6. Jefford M, Ward AC, Lisy K, et al. Patient-reported outcomes in cancer survivors: a population-wide cross-sectional study. Support Care Cancer. 2017;25:3171-9. CrossRef

7. Brown LF, Kroenke K, Theobald DE, Wu J, Tu W. The association of depression and anxiety with health-related quality of life in cancer patients with depression and/or pain. Psychooncology. 2010;19:734-41. CrossRef

8. Institute of Medicine (US) Committee on Psychosocial Services to Cancer Patients/Families in a Community Setting; Adler NE, Page AEK (eds). Cancer Care for the Whole Patient: Meeting Psychosocial Health Needs. Washington, DC: National Academies Press (US), 2008.

9. Andersen BL, DeRubeis RJ, Berman BS, et al. Screening, assessment, and care of anxiety and depressive symptoms in adults with cancer: an American Society of Clinical Oncology guideline adaptation. J Clin Oncol. 2014;32:1605-19. CrossRef

10. Forsythe LP, Kent EE, Weaver KE, et al. Receipt of psychosocial care among cancer survivors in the United States. J Clin Oncol. 2013;31:1961-9. CrossRef

11. Cutshall SM, Cha SS, Ness SM, et al. Symptom burden and integrative medicine in cancer survivorship. Support Care Cancer. 2015;23:2989-94. CrossRef

12. Martin LA, Moye J, Street RL Jr, Naik AD. Reconceptualizing cancer survivorship through veterans' lived experiences. J Psychosoc Oncol. 2014;32:289-309. CrossRef

13. Deimling GT, Brown SP, Albitz C, Burant CJ, Mallick N. The relative importance of cancer-related and general health worries and distress among older adult, long-term cancer survivors. Psychooncology. 2017;26:182-90. CrossRef

14. Firmin MW, Pathammavong MB, Johnson CB, Trudel JF. Anxiety experienced by individuals with cancer in remission. Psychol Health Med. 2014;19:153-8. CrossRef

15. Arrieta $\mathrm{O}$, Angulo LP, Núñez-Valencia $C$, et al. Association of depression and anxiety on quality of life, treatment adherence, and prognosis in patients with advanced non-small cell lung cancer. Ann Surg Oncol. 2013;20:1941-8. CrossRef

16. Bujang MA, Musa R, Liu WJ, Chew TF, Lim CT, Morad Z. Depression, anxiety and stress among patients with dialysis and the association with quality of life. Asian $J$ Psychiatr. 2015;18:49-52. CrossRef

17. Villeneuve C, Rousseau A, Rerolle JP, et al. Adherence profiles in kidney transplant patients: causes and consequences. Patient Educ Couns. 2020;103:189-98. CrossRef

18. Mutsaers B, Jones G, Rutkowski N, et al. When fear of cancer recurrence becomes a clinical issue: a qualitative analysis of features associated with clinical fear of cancer recurrence. Support Care Cancer. 2016;24:4207-18. CrossRef

19. Ratcliff C, Naik AD, Martin LA, Moye J. Examining cancer survivorship trajectories: exploring the intersection between qualitative illness narratives and quantitative screening instruments. Palliat Support Care. 2018;16:712-8. CrossRef

20. Klabunde CN, Ambs A, Keating NL, et al. The role of primary care physicians in cancer care. J Gen Intern Med. 2009;24:1029-36. $\underline{\text { CrossRef }}$
21. Meiklejohn JA, Mimery A, Martin JH, et al. The role of the GP in follow-up cancer care: a systematic literature review. J Cancer Surviv. 2016;10:990-1011. CrossRef

22. Creswell JW, Creswell JD. Research Design: Qualitative, Quantitative, and Mixed Methods Approaches, Fifth Edition. Thousand Oaks, CA: SAGE Publications, 2018.

23. Krueger RA, Casey MA. Focus Groups: A Practical Guide for Applied Research, 3rd Edition. Thousand Oaks, CA: SAGE Publications, 2000.

24. Charmaz K. Constructing Grounded Theory: A Practical Guide Through Qualitative Analysis. Thousand Oaks, CA: SAGE Publications, 2006.

25. Kenyon M, Mayer DK, Owens AK. Late and long-term effects of breast cancer treatment and surveillance management for the general practitioner. J Obstet Gynecol Neonatal Nurs. 2014;43:382-98. CrossRef

26. Kantsiper M, McDonald EL, Geller G, Shockney L, Snyder C, Wolff AC. Transitioning to breast cancer survivorship: perspectives of patients, cancer specialists, and primary care providers. J Gen Intern Med. 2009;24 Suppl 2:S459-66. CrossRef

27. McCabe MS, Bhatia S, Oeffinger KC, et al. American Society of Clinical Oncology statement: achieving high-quality cancer survivorship care. J Clin Oncol. 2013;31:631-40. CrossRef

28. Ganz PA, Kwan L, Somerfield MR, et al. The role of prevention in oncology practice: results from a 2004 survey of American Society of Clinical Oncology members. J Clin Oncol. 2006;24:2948-57. CrossRef

29. Welsch S, Hense HW, Groll A, et al. [Adherence to long-term follow-up in paediatric oncology - results of a monocentric analysis]. Klin Padiatr. 2015;227:144-50. CrossRef

30. Luctkar-Flude M, Aiken A, McColl MA, Tranmer J, Langley H. Are primary care providers implementing evidence-based care for breast cancer survivors? Can Fam Physician. 2015;61:978-84.

31. Tilburt JC, Kelley S, DeCourtney CA, Humeniuk KM, Latini J, Kim SP. Caring for Alaska Native prostate cancer survivors in primary care: a survey of Alaska Tribal Health System providers. Int J Circumpolar Health. 2014;73:23637. CrossRef

32. Wilbur J. Surveillance of the adult cancer survivor. Am Fam Physician. 2015;91:29-36.

33. Weaver KE, Aziz NM, Arora NK, et al. Follow-up care experiences and perceived quality of care among long-term survivors of breast, prostate, colorectal, and gynecologic cancers. J Oncol Pract. 2014;10:e231-9. CrossRef

34. Jain J, Qorri B, Szewczuk MR. The crucial role of primary care providers in the long-term follow-up of adult survivors of childhood cancer. Cancer Manag Res. 2019;11:3411-8. CrossRef

35. Caspari JM, Raque-Bogdan TL, McRae C, Simoneau TL, Ash-Lee S, Hultgren K. Posttraumatic growth after cancer: the role of perceived threat and cognitive processing. J Psychosoc Oncol. 2017;35:561-77. CrossRef

36. Blanch-Hartigan D, Forsythe LP, Alfano CM, et al. Provision and discussion of survivorship care plans among cancer survivors: results of a nationally representative survey of oncologists and primary care physicians. J Clin Oncol. 2014;32:1578-85. CrossRef

37. Karageorge A, Murphy MJ, Newby JM, et al. Acceptability of an internet cognitive behavioural therapy program for people with early-stage cancer and cancer survivors with depression and/or anxiety: thematic findings from focus groups. Support Care Cancer. 2017;25:2129-36. CrossRef

(C) 2020 Aurora Health Care, Inc. 